\title{
SISTEM PENGAMBILAN KEPUTUSAN METODE KONSTRUKSI BERBASIS ANALYTICAL HIERARCHY PROCESS
}

\author{
Jojok Widodo Soetjipto', Muhammad Nur Hanafi², dan Sri Sukmawati ${ }^{3}$
}

\author{
1Prodi Teknik Sipil, Universitas Jember, Jl. Kalimantan 37, Jember, 68120 \\ Email korespondensi: jojok.teknik@unej.ac.id \\ ${ }^{2}$ Prodi Teknik Sipil, Universitas Jember, Jl. Kalimantan 37, Jember, 68120 \\ Email : nur.hanafi277@gmail.com \\ 3Prodi Teknik Sipil, Universitas Jember, Jl. Kalimantan 37, Jember, 68120 \\ Email : srisukmawati67@gmail.com
}

\begin{abstract}
ABSTRAK
Proyek Apartemen Grand Shamaya Surabaya merupakan salah satu proyek gedung tinggi di Surabaya yang dibangun di atas lahan yang memiliki kondisi tanah yang buruk dan sempit serta berada di antara gedung tinggi yang berdekatan. Pada pekerjaan basement gedung ini memerlukan metode pelaksanaan yang tepat karena metode pelaksanaan ini sangat berpengaruh terhadap ketercapaian tujuan proyek (biaya, mutu dan waktu). Oleh karena itu perlu adanya analisa yang mendalam dengan mempertimbangkan semua variabel yang berpengaruh dalam penentuan metode konstruksi. Salah satu metode yang dapat diaplikasikan untuk membantu dalam pengambilan keputusan metode konstruksi yang tepat adalah Metode Analytical Hierarchy Process (AHP). Metode ini memiliki kemampuan dalam menyusun skala prioritas (sebagai faktor bobot) dari variabel yang kompleks dan mudah diaplikasikan, sehingga metode ini dapat dijadikan alat untuk pengambilan keputusan penentuan metode konstruksi yang mudah dan cepat. Pengambilan data dilakukan melalui kuisioner dan indepth interview dengan responden yang memiliki kepakaran (pengetahuan, pengalaman, dan keterampilan yang baik dalam penyusunan metode konstruksi). Hasil penelitian menunjukkan bahwa metode AHP ini dapat disusun sebagai sistem pengambilan keputusan penentuan metode konstruksi pekerjaan basement dengan tepat. Bobot prioritas yang dihasilkan dari AHP dapat dijadikan parameter untuk menentukan nilai keputusan penentuan metode konstruksi berdasarkan ketersediaan sumber daya yang dimiliki pada proyek tersebut.
\end{abstract}

Kata kunci: Sistem pengambil keputusan, Metode konstruksi, AHP, Tujuan proyek, Pekerjaan Basement.

\begin{abstract}
The Grand Shamaya Surabaya Apartment Project is one of the high-rise building projects in Surabaya, built on-site with poor and narrow soil conditions and is located between close the highrise buildings. In basement work, this building requires an appropriate implementation method because this implementation method greatly influences the achievement of project goal (cost, quality, and time). Therefore it is necessary to have an in-depth analysis by considering all the variables that influence the construction method's determination. One method that can be applied to assist in making decisions about the appropriate construction method is the Analytical Hierarchy Process (AHP) method. This method has the ability to arrange a priority scale (as a weighting factor) of complex variables. It is easy to apply so that this method can be used to make decisions about construction methods both easily and fastly. Data were collected through questionnaires and in-depth interviews with respondents who have expertise (good knowledge, experience, and skills in construction methods). The results showed that the AHP could become a decision support system for determining the basement construction method exactly. The priority weight generated from AHP can be used as a parameter to determine the value of the decision to determine the construction method based on availability of project's existing resources.
\end{abstract}

Keywords: Decision Support System, Construction method, AHP, Project goals, Basement work. 


\section{PENDAHULUAN}

Proyek Pembangunan Apartemen Grand Shamaya Surabaya merupakan salah satu proyek gedung tinggi di Kota Surabaya. Proyek ini memiliki kompeksitas pekerjaan yang tinggi dengan anggaran yang sangat besar serta memiliki alokasi waktu pelaksanaan yang sangat ketat. Data menunjukkan bahwa proyek ini sudah mengalami keterlambatan dengan deviasi sebesar $12,29 \%$ terhitung per minggu ketiga Januari 2020. Hal ini dikarenakan adanya kendala pada produktivitas tenaga kerja yang rendah, kinerja dari subkontraktor yang kurang memuaskan, ruang lingkup pekerjaan yang sangat komplek, site proyek yang terbatas, pelaksanaaan yang kurang terstruktur, finansial proyek yang terganggu dan lain-lain.

Kinerja proyek ini akan selalu mengalami gangguan jika tidak segera dilakukan perbaikan perencanaan pekerjaan dengan baik. Kinerja ini akan mempengaruhi capaian tujuan proyek yaitu biaya, waktu, dan mutu. Capaian tujuan proyek ini akan sangat tergantung pada bagaimana pelaksanaan pekerjaan tersebut dapat disusun dengan baik. Perencanaan pelaksanaan pekerjaan harus disusun berdasarkan kemampuan proyek dalam menyelesaian semua faktor permasalahan yang akan terjadi pada proyek tersebut. Faktor-faktor yang dapat menjadi penyebab permasalahan pekerjaan di proyek sangat banyak dan memiliki hubungan yang sangat komplek. Oleh karena itu diperlukan sebuah sistem pengambilan keputusan dalam penentuan rencana pelaksanaan pekerjaan tersebut.

Sistem pengambilan keputusan (Decision Support System/DSS) dapat membantu menentukan pemilihan metode konstruksi yang tepat. DSS disusun dengan mempertimbangkan kesesuaian antara ketersediaan sumber daya yang dimiliki dengan kondisi variabel permasalahan yang diperkirakan dapat terjadi di proyek. Sumber daya yang diperlukan dalam proyek meliputi sumber daya manusia, peralatan konstruksi, material konstruksi, kebutuhan keuangan dan metode konstruksi. Variabel permasalahan proyek selalu dihubungkan dengan tujuan proyek yaitu biaya, mutu dan waktu. Setiap proyek diharuskan dapat melaksanakan semua scope of work yang telah ditetapkan dalam kontrak sesuai dengan anggaran biaya yang tersedia, waktu yang telah ditetapkan dan kualitas yang telah disepakati.

Berdasarkan data dan permasalahan yang telah dijelaskan di atas, maka pada penelitian ini akan mendiskusikan tentang:

a. Bagaimana AHP dapat digunakan untuk menyelesaikan permasalahan pemilihan metode konstruksi di proyek berdasarkan variabel yang sangat kompleks?

b. Bagaimana menyusun DSS berbasis AHP untuk membantu pengambilan keputusan pemilihan metode konstruksi di proyek?

c. Bagaimana cara review dan validasi luaran DSS melalui penilaian keputusan pemilihan metode konstruksi di proyek?

\section{KERANGKA PENELITIAN}

KONSEPTUAL

Penelitian ini memiliki tujuan untuk menyusun model DSS berbasis AHP dalam rangka menentukan metode konstruksi yang tepat. Model DSS disusun dengan mempertimbangkan tujuan/goal proyek yang diselaraskan dengan faktor-faktor yang mempengaruhi metode pelaksanaan proyek. Keputusan yang dihasilkan dari model DSS ini harus dapat memasukkan data sumber daya yang dimiliki proyek dengan potensi permasalahan yang diperkirakan dapat terjadi. Kerangka konseptual penelitian dapat dilihat pada Gambar 1. 


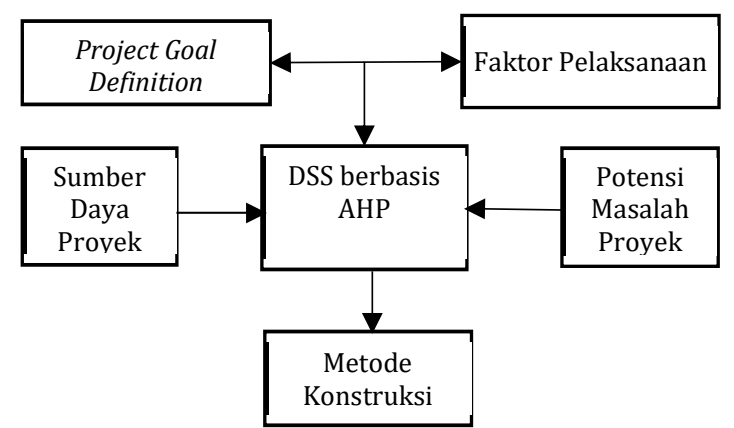

Gambar 1. Kerangka Konseptual

\section{METODE KONSTRUKSI}

Metode konstruksi disusun berdasarkan landasan filosofi yang terbentuk dari hasil studi ilmu pengetahuan dan seni [1]. Unsurunsur yang harus dipertimbangkan dalam penyusunan metode konstruksi meliputi:
a. Rasional
b. Tanggap melihat bagian-bagian yang krusial
c. Sistematik
d. Pragmatis/berwawasan luas
e. Praktis
f. Berkemampuan menilai
g. Dapat melihat tingkat prioritas
h. Mengantisipasi permasalahan dan konsukuensi
i. Berorientasi pada tingkat dan variasi resiko
j. Berlandaskan penguasaan variasi sistem struktur dan metode konstruksi dengan persyaratan dan limitasinya.

\section{KONSTRUKSI BASEMENT}

Basement adalah perluasan ruang pada bangunan gedung bertingkat secara vertikal yang terdiri dari satu lantai atau lebih yang berada di bawah tanah dengan memaksimalkan lahan dan konstruksi bawah sebagai salah satu penopangnya. Basement pada bangunan gedung bertingkat umumnya dimanfaatkan sebagai lahan parkir. Selain itu, basement juga bisa dimanfaatkan sebagai utilitas utama atau tambahan dari bangunan itu sendiri [2].
Secara umum metode konstruksi pada pekerjaan basement memiliki 2 metode yaitu:

a. Metode Konstruksi Bottom Up: Metode konstruksi ini dilaksanakan dengan galian tanah sampai dengan elevasi terendah sesuai dengan perencanaan. Pelat basement yang paling bawah dicor dan diselesaikan terlebih dahulu sehingga terbentuk Raft Foundation, kemudian pekerjaan struktur basement diselesaikan dari bawah ke atas. Kolom dan balok dilakukan dengan cor in situ [3] dan [4].

b. Metode Konstruksi Top Down: Metode konstruksi ini dilakukan dengan pelaksanaan pekerjaan yang bersamaan antara struktur atas dengan struktur bawah. Pada metode ini, pekerjaan galian basement dilaksanakan bersamaan dengan pekerjaan struktur atas seperti kolom, balok dan pelat yang dikerjakan lantai per lantai kebawah sampai dengan elevasi basement yang direncanakan. Selama proses pekerjaan kolom, balok dan pelat, didukung oleh tiang kolom baja yang disebut dengan king post [3], [4] dan [5].

\section{ANALYTICAL HIERARCHY PROCESS (AHP)}

Metode Analytical Hierarchy Process (AHP) merupakan sebuah metode pendukung untuk membantu menentukan sebuah keputusan atas beberapa alternatif pilihan. Metode ini akan menguraikan masalah multi kriteria yang kompleks menjadi satu struktur hirarki. Hirarki merupakan representasi dari permasalahan yang kompleks pada multi kriteria di dalam suatu struktur multilevel. Level pertama adalah tujuan, kedua adalah level faktor/kriteria, sub kriteria, dan seterusnya hingga level yang terakhir dari alternatif [6]. Metode AHP sudah diaplikasikan pada penelitian pemilihan kontraktor [7], metode seleksi suplier [8] dan [9], analisis prioritas pembangunan embung [10], dan lain-lain. 
Secara garis besar, tahapan-tahapan dalam metode AHP adalah sebagai berikut [10] dan [6]:

a. Mendefinisikan permasalahan dan solusi yang dibutuhkan.

b. Membuat struktur hirarki berdasarkan tujuan.

c. Membuat matriks perbandingan berpasangan yang menggambarkan kontribusi relatif atau pengaruh tiap elemen terhadap kriteria yang satu tingkat di atasnya.

d. Mendefinisikan matriks perbandingan berpasangan sehingga diperoleh jumlah penilaian keseluruhan sebanyak $\mathrm{n} x$ [(n1)/2], dengan nilai $n$ adalah banyaknya jumlah kriteria atau elemen yang dibandingkan.

e. Menghitung nilai eigen dan konsistensinya, apabila dinilai tidak konsisten, maka pengambilan data dapat ditinjau kembali.

f. Mengulangi langkah-langkah pada poin c, d dan e untuk semua tingkat struktur hirarki.

g. Menghitung vektor eigen dari setiap matriks perbandingan berpasangan untuk menentukan prioritas elemen pada setiap tingkat hirarki dari terendah sampai dengan tujuan utama.

\section{METODE PENELITIAN}

Jenis penelitian yang digunakan adalah penelitian deskriptif. Penelitian ini bertujuan untuk menemukan suatu metode pengukuran berbasis AHP dengan memasukkan faktor-faktor yang berpengaruh terhadap penyusunan metode konstruksi. Faktor-faktor ini akan dihubungkan dengan tujuan proyek yaitu biaya, mutu dan waktu.

DSS dapat dibentuk berdasarkan data pengamatan dan pendapat dari responden. Variabel dan data penelitian akan dikonfirmasikan kepada expert/pakar untuk memastikan bahwa variabel penelitian memang benar-benar terjadi pada proyek. Jika variabel tersebut sudah terkonfirmasi, maka data dari variabel tersebut akan dikumpulkan melalui pengisian kuisioner untuk melihat perilaku dan sebaran pandangan responden. Untuk memastikan bahwa semua perilaku dan hasil penelitian sesuai dengan pengalaman di proyek, maka dilakukan validasi model melalui indepthinterview kepada para pakar yang berkompeten pada proyek studi kasus.

Penentuan responden menggunakan metode purposive sampling pada karyawan proyek. Karyawan yang dipilih memiliki jabatan minimal sebagai site enginer dengan pengalaman di proyek minimal 5 tahun. Jumlah responden yang dipilih adalah 8 orang. Sedangkan penentuan pakar dilakukan berdasarkan pengetahuan, pengalaman dan keterampilan yang dimiliki berkaitan dengan penyusunan rencana pelaksanaan proyek konstruksi. Pakar yang dipakai pada penelitian untuk proses validasi yaitu Project Manager, Site Manager dan Site Engineer.

Seluruh variabel dalam penelitian ini diukur menggunakan skala saaty (sesuai dengan metode AHP) dengan membandingkan dua variabel. Penilaian dilakukan dengan memberikan nilai berdasarkan skala intensitas kepentingan kedua variabel tersebut. Penilaian ini akan menghasilkan nilai prioritas yang selanjutnya dapat dijadikan nilai bobot (weight) suatu variabel dalam menentukan pilihan.

Pakar akan melakukan validasi atas penilaian variabel dari setiap metode konstruksi yang diusulkan. Metode konstruksi dengan nilai terbesar merupakan pilihan yang tepat karena sudah sesuai dengan prioritas dan penilaian variabel.

\section{ANALISIS DAN PEMBAHASAN}

Pada penelitian ini, analisis dilakukan menggunakan metode penelitian yang telah diuraikan di atas. Pada setiap tahapan pembahasan akan dilakukan diskusi dan penjelasan terhadap hasil yang diperoleh dari penelitian tersebut. 


\section{Kriteria penyusunan metode konstruksi}

Variabel yang mempengaruhi penyusunan metode konstruksi sudah didefinisikan berdasarkan studi literatur. Namun variabel ini dilakukan konfirmasi kepada pakar melalui wawancara untuk menentukan variabel yang sesuai dengan studi kasus ini. Hasil wawancara dengan para pakar diperoleh variabel yang mempengaruhi penyusunan metode konstruksi adalah sebagai berikut:

1. Biaya
a. Produktivitas tenaga kerja
b. Kenaikan harga material
c. Kerusakan material
d. Pengetahuan dan pengalaman
e. Metode kerja kurang tepat
f. Perubahan desain
g. Respon masyarakat

2. Mutu
a. Pengkajian gambar
b. Inspeksi alat
c. Pengujian sampling
d. Monitoring pekerjaan
e. Supervisi
f. Pemilihan vendor
g. Ketepatan metode kerja

3. Waktu
a. Produktivitas tenaga kerja
b. Ketersediaan material
c. Ketersediaan peralatan
d. Karakteristik lingkungan proyek
e. Manajerial proyek
f. Finansial proyek
g. Kecelakaan kerja
h. Penerapan teknologi
i. Intensitas hujan

\section{Penyusunan hirarki AHP metode konstruksi}

Hirarki AHP metode konstruksi merupakan bentuk penyederhanaan variabel penentu metode konstruksi yang komplek menjadi struktur multilevel dengan berdasarkan tujuan dari setiap level tersebut. Level pertama merupakan tujuan (goal), level kedua merupakan kriteria, dan level ketiga sub kriteria. Setiap level memiliki variabel sesuai perilaku dan struktur dengan pendekatan perilaku sesungguhnya. Bentuk hirarki AHP metode konstruksi berdasarkan variabel terkonfirmasi dapat dilihat pada Gambar 2.

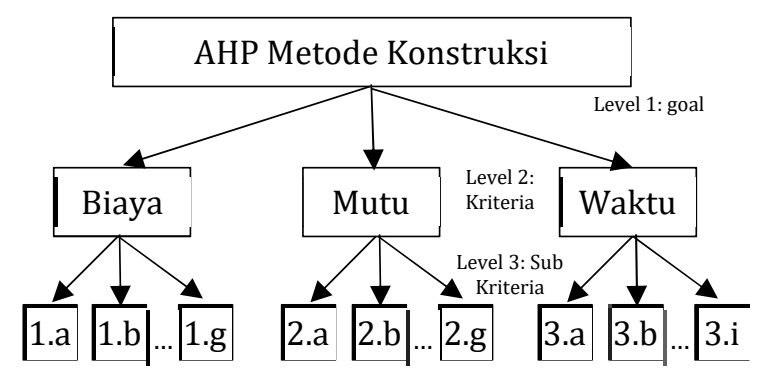

Gambar 2. Hirarki AHP Metode Konstruksi

\section{Matriks perbandingan (pairwase comparison) jawaban responden}

Dari data kuisiner yang sudah dikumpulkan dan diakumulasikan menggunakan rata-rata geometri (lihat persamaan 1), diperoleh matriks perbandingan berpasangan untuk level kriteria seperti pada Tabel 1 berikut.

$$
G=\sqrt[n]{x_{1} \times x_{2} \times \ldots \times x_{n}}
$$

dengan $\mathrm{G}=$ rata-rata geometri dari respon responden, $\mathrm{x}_{\mathrm{n}}=$ respon responden.

Tabel 1. Matriks Perbandingan Berpasangan Kriteria

\begin{tabular}{llll}
\hline Kriteria & Waktu & Biaya & Mutu \\
\hline Waktu & 1 & 3.8845 & 0.2915 \\
Biaya & 0.2574 & 1 & 0.1975 \\
Mutu & 3.4309 & 5.0633 & 1 \\
\hline
\end{tabular}

Sedangkan untuk level sub kriteria biaya, sub kriteria mutu dan sub kriteria waktu dapat dilakukan dengan cara yang sama pada level kriteria.

Setelah diperoleh matrik perbandingan berpasangan dari masing-masing kriteria dan sub kriteria, langkah selanjutnya adalah melakukan perhitungan normalisasi 
matriks untuk memperoleh hasil nilai eigen. Nilai eigen akan digunakan untuk menentukan bobot dan urutan prioritas dari kriteria dan sub kriteria. Adapun hasil bobot dan prioritas kriteria, sub kriteria biaya, sub kriteria mutu dan sub kriteria waktu dapat dilihat pada Tabel 2, Tabel 3, Tabel 4 dan Tabel 5.

Tabel 2. Bobot dan Prioritas Kriteria

\begin{tabular}{clrr}
\hline Ranking & Item & Eigen & Bobot (\%) \\
\hline 1 & Mutu & 0.6375 & 63.7465 \\
2 & Waktu & 0.2665 & 26.6510 \\
3 & Biaya & 0.0960 & 9.6025 \\
\hline
\end{tabular}

Tabel 3. Bobot dan Prioritas Sub-faktor Biaya

\begin{tabular}{|c|c|c|c|}
\hline Ranking & Item & Eigen $b$ & obot (\%) \\
\hline 1 & $\begin{array}{l}\text { Ketepatan metode } \\
\text { pelaksanaan }\end{array}$ & 0.1760 & 17.6011 \\
\hline 2 & $\begin{array}{l}\text { Kenaikan harga } \\
\text { material }\end{array}$ & 0.1755 & 17.5501 \\
\hline 3 & $\begin{array}{l}\text { Pengalaman dan } \\
\text { pengetahuan } \\
\text { subkontraktor }\end{array}$ & 0.1727 & 17.2663 \\
\hline 4 & Perubahan desain & 0.1602 & 16.0158 \\
\hline 5 & Kerusakan material & 0.1414 & 14.1410 \\
\hline 6 & Respon masyarakat & 0.0978 & 9.7843 \\
\hline 7 & $\begin{array}{l}\text { Produktivitas } \\
\text { tenaga kerja }\end{array}$ & 0.0764 & 7.6414 \\
\hline
\end{tabular}

Tabel 4. Bobot dan Prioritas Sub-faktor Mutu

\begin{tabular}{clcc}
\hline Ranking & Item & Eigen & Bobot (\%) \\
\hline 1 & $\begin{array}{l}\text { Pengkajian } \\
\text { gambar }\end{array}$ & 0.1922 & 19.2245 \\
2 & $\begin{array}{l}\text { Monitoring } \\
\text { pekerjaan }\end{array}$ & 0.1804 & 18.0381 \\
3 & $\begin{array}{l}\text { Pengujian } \\
\text { sampling }\end{array}$ & 0.1406 & 14.0629 \\
4 & $\begin{array}{l}\text { Ketepatan } \\
\text { metode }\end{array}$ & 0.1250 & 12.5037 \\
5 & $\begin{array}{l}\text { Pemilihan } \\
\text { vendor }\end{array}$ & 0.1228 & 12.2791 \\
& & &
\end{tabular}

\begin{tabular}{cccc}
\hline Ranking & \multicolumn{1}{c}{ Item } & Eigen & Bobot (\%) \\
\hline 6 & Inspeksi alat & 0.1212 & 12.1183 \\
7 & Supervisi & 0.1177 & 11.7734 \\
\hline
\end{tabular}

Tabel 5. Bobot dan Prioritas Sub-faktor Waktu

\begin{tabular}{clcc}
\hline Ranking & \multicolumn{1}{c}{ Item } & Eugen & Bobot (\%) \\
\hline 1 & Manajerial proyek & 0.1436 & 14.3565 \\
2 & Kecelakaan kerja & 0.1374 & 13.7384 \\
3 & Finansial proyek & 0.1342 & 13.4189 \\
4 & $\begin{array}{l}\text { Ketersediaan } \\
\text { peralatan }\end{array}$ & 0.1340 & 13.4036 \\
5 & $\begin{array}{l}\text { Ketersediaan } \\
\text { material }\end{array}$ & 0.1271 & 12.7145 \\
6 & $\begin{array}{l}\text { Penerapan } \\
\text { teknologi }\end{array}$ & 0.0885 & 8.8485 \\
7 & $\begin{array}{l}\text { Produktivitas } \\
\text { tenaga kerja }\end{array}$ & 0.0884 & 8.8385 \\
8 & $\begin{array}{l}\text { Karakteristik } \\
\text { lingkungan } \\
\text { proyek }\end{array}$ & 0.0766 & 7.6601 \\
9 & $\begin{array}{l}\text { Intensitas curah } \\
\text { hujan }\end{array}$ & 0.0702 & 7.0210 \\
\hline
\end{tabular}

Setelah bobot dan prioritas tiap elemen kriteria dan sub kriteria sudah diperoleh, maka langkah selanjutnya adalah melakukan uji konsistensi tiap-tiap elemen untuk mengetahui tingkat konsistensinya. Hasil uji konsistensi dapat dilihat pada Tabel 6. Dari tabel ini dapat dilihat bahwa semua perhitungan pembobotan sudah memiliki uji konsistensi yang sesuai ketentuan yaitu < $10 \%$.

Tabel 6. Uji Konsistensi Matriks Kriteria dan Sub Kriteria

\begin{tabular}{|c|c|c|c|c|}
\hline Variabel & Kriteria & $\begin{array}{c}\text { Sub } \\
\text { Kriteria } \\
\text { Waktu }\end{array}$ & $\begin{array}{c}\text { Sub } \\
\text { Kriteria } \\
\text { Biaya }\end{array}$ & $\begin{array}{c}\text { Sub } \\
\text { Kriteria } \\
\text { Mutu }\end{array}$ \\
\hline $\mathrm{n}$ & 3 & 9 & 7 & 7 \\
\hline RI & 0.58 & 1.45 & 1.32 & 1.32 \\
\hline$\lambda_{\text {maks }}$ & 3.1065 & 9.7634 & 8.7972 & 7.6227 \\
\hline CI & 0.0532 & 0.0954 & 0.1139 & 0.1038 \\
\hline
\end{tabular}




\begin{tabular}{lcccc}
\hline Variabel & Kriteria & $\begin{array}{c}\text { Sub } \\
\text { Kriteria } \\
\text { Waktu }\end{array}$ & $\begin{array}{c}\text { Sub } \\
\text { Kriteria }\end{array}$ & $\begin{array}{c}\text { Sub } \\
\text { Briteria }\end{array}$ \\
\hline CR & & Mutu \\
\hline Konsistensi & OK & OK & OK & OK \\
\hline
\end{tabular}

\section{Luaran metode AHP}

Analisa AHP dapat memberikan nilai bobot prioritas setiap variabel yang terkofirmasi mempengaruhi dalam pemilihan metode konstruksi tersebut. Nilai bobot ini diperoleh dari penilaian para pakar yang memiliki pengetahuan, pengalaman dan keterampilan yang baik dalam menyusun metode konstruksi. Luaran AHP dapat dilihat pada Tabel 7. Pada luaran analisa AHP ini diperoleh nilai bobot prioritas kriteria dan sub kriteria yang digabungkan dalam satu kolom. Nilai prioritas pada kriteria dan sub kriteria ini akan dijadikan faktor bobot variabel yang dihitung secara simultan agar prioritas setiap level dapat dihitung pengaruhnya.

Tabel 7. Luaran AHP Metode Konstruksi

\begin{tabular}{|c|c|c|c|}
\hline No & Variabel & \multicolumn{2}{|c|}{ Bobot (\%) } \\
\hline & & & \\
\hline 1 & Manajerial proyek & \multirow{9}{*}{ 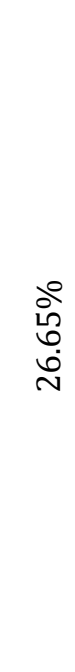 } & 14.3565 \\
\hline 2 & Kecelakaan kerja & & 13.7384 \\
\hline 3 & Finansial proyek & & 13.4189 \\
\hline 4 & $\begin{array}{l}\text { Ketersediaan } \\
\text { peralatan }\end{array}$ & & 13.4036 \\
\hline 5 & Ketersediaan material & & 12.7145 \\
\hline 6 & Penerapan teknologi & & 8.8485 \\
\hline 7 & $\begin{array}{l}\text { Produktifitas tenaga } \\
\text { kerja }\end{array}$ & & 8.8385 \\
\hline 8 & $\begin{array}{l}\text { Karakteristik } \\
\text { lingkungan proyek }\end{array}$ & & 7.6601 \\
\hline 9 & Intensitas curah hujan & & 7.0210 \\
\hline B & Sub Kriteria: biaya & & \\
\hline 1 & $\begin{array}{l}\text { Ketepatan metode } \\
\text { pelaksanaan }\end{array}$ & \multirow{2}{*}{$\begin{array}{l}\text { oे } \\
\text { Oे } \\
\text { ö }\end{array}$} & 17.6011 \\
\hline 2 & $\begin{array}{l}\text { Kenaikan harga } \\
\text { material }\end{array}$ & & 17.5501 \\
\hline
\end{tabular}

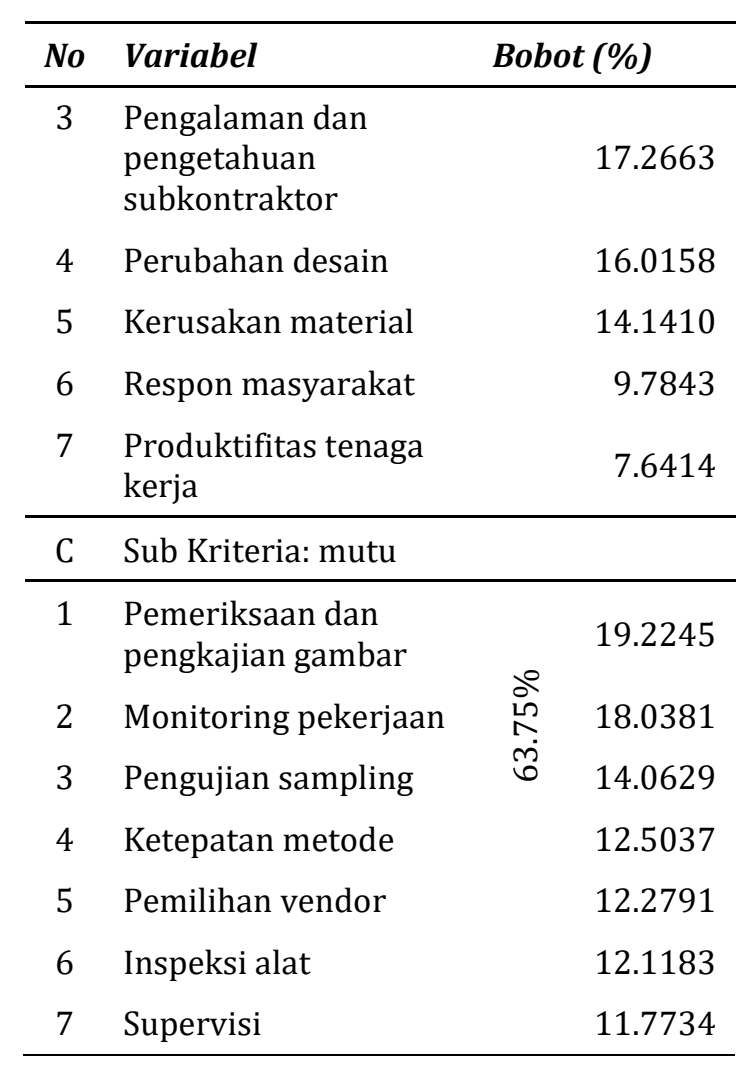

Hasil analisis AHP menunjukkan bahwa dalam menyusun metode konstruksi pekerjaan basement, para pakar menilai bahwa mutu merupakan kriteria utama yang harus diperhatikan dengan nilai bobot $63.75 \%$ sedangkan yang kedua dan ketiga adalah kriteria waktu dan biaya masingmasing $26.65 \%$ dan $9.60 \%$. Pekerjaan basement merupakan starting point dari pekerjaan gedung karena semua pekerjaan lain sangat tergantung dari keberhasilan pekerjaan ini. Sehingga tim proyek cenderung memberikan respon untuk mengutamakan mutu dan waktu dibanding biaya.

Pada sub kriteria waktu, biaya dan mutu memiliki variabel prioritas yang berbedabeda. Sub kriteria waktu memiliki variabel utama yang harus diperhatikan yaitu variabel manajerial proyek dan variabel kecelakaan kerja. Sub kriteria biaya menempatkan variabel ketepatan metode pelaksanaan dan variabel kenaikan harga material sebagai variabel yang sangat berpengaruh terhadap biaya. Sedangkan sub kriteria mutu, variabel pemeriksaan dan pengkajian gambar dan variabel monitoring 
pekerjaan merupakan variabel prioritas yang harus dikendalikan.

Selanjutnya, hasil dari penilaian prioritas pada AHP akan dijadikan alat untuk membantu mengambil keputusan dalam pemilihan alternatif metode konstruksi yang diusulkan dalam pekerjaan basement. Hasil AHP akan dimodifikasi dan diverifikasi agar dapat dijadikan sebagai Model Sistem Pengambilan Keputusan/Decision Support System (DSS).

\section{Model sistem pengambilan keputusan/ Decision Support System (DSS) berbasis AHP}

DSS merupakan sebuah sistem yang sangat diperlukan oleh pengambil kebijakan untuk membantu menentukan variasi pilihan yang memiliki variabel yang kompleks dan membutuhkan penilaian yang rumit. Penelitian DSS secara umum menghasilkan sebuah sistem yang dapat dijadikan sebagai alat bantu menilai suatu pilihan berdasarkan fenomena/perilaku variabel yang sangat banyak dan kompleks. Beberapa penelitian terkait DSS sudah dilakukan meliputi penggunaan DSS dalam penyelesaian konflik pada konstruksi [11], DSS pada proses tender konstruksi [12], pemilihan karyawan terbaik [13], penentuan siswa berprestasi [14], dan lainlain.

Untuk menyusun DSS, maka diperlukan analisis yang mendalam mengenai hubungan antara pengambil keputusan, manajemen data, sistem pengolah data, dan data eksternal (sebagai varian pilihan). Hubungan antar bagian dalam DSS dibuat dalam bentuk diagram agar dapat disusun dengan baik. Skematik DSS pada penelitian ini dapat dilihat pada Gambar 3.

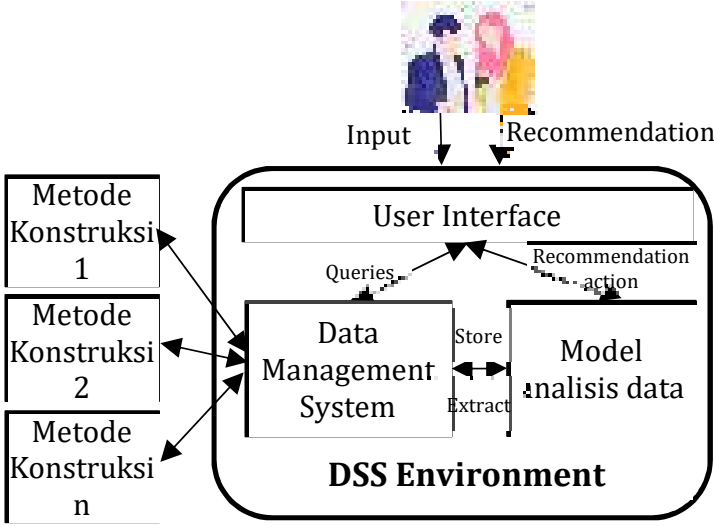

Gambar 3. Skematik Penyusunan Model DSS

DSS pada penelitian ini didesain untuk membantu pengambil keputusan dalam menentukan metode konstruksi yang tepat agar dapat mencapai tujuan proyek dengan baik. Tujuan proyek yang dimaksud meliputi memenuhi biaya yang dianggarkan, mutu yang telah ditetapkan dan alokasi waktu yang sudah disepakati. Berdasarkan Gambar 3, maka susunan DSS ini meliputi:

a. Pengambil Keputusan

Pihak ini akan memberikan input sebagai intepretasi data sumber daya yang dimiliki. Selain itu mereka juga akan menilai dan mereview hasil rekomendasi dari luaran DSS tersebut.

b. User Interface

Bagian ini akan membantu menterjemahkan data yang diinputkan ke manajemen data dan proses analisis data. Dan sebaliknya, bagian ini juga akan memberikan penjelasan atas luaran rekomendasi yang dihasilkan oleh DSS.

c. Data Management System

Data manajemen sistem adalah hasil penilaian variabel-variabel yang mempengaruhi metode konstruksi berdasarkan ketersediaan sumber daya yang dimiliki sesuai dengan pilihan metode konstruksi yang diusulkan. Dalam penelitian ini, penilaian variabel masih dilakukan secara manual berdasarkan ketersediaan sumber daya secara berulang-ulang sesuai jumlah metode konstruksi yang diusulkan. 
Penilainya juga membutuhkan pakar yang berpengalaman di bidang metode konstruksi yang diusulkan.

d. Model Analisis Data

Model analisis data merupakan model luaran dari AHP yang sudah dimodifikasi/verifikasi. Model ini akan memproses data yang terdapat pada manajemen data dan divalidasi oleh pakar/ahli.

e. Metode Konstruksi

Metode Konstruksi yang dimaksud dalam skematik ini adalah penentuan karakteristik, perilaku, dan sifat dari metode konstruksi yang diusulkan untuk diselaraskan dengan penilaian variabel pada metode konstruksi tersebut.

\section{Hasil analisis sistem pengambilan keputusan/Decision Support System (DSS) berbasis AHP}

Pada penelitian ini akan membandingkan 2 metode konstruksi pada pekerjaan basemen yaitu: (i) metode konstruksi top-down; dan (ii) metode konstruksi bottom-up. Variabelvariabel pada kedua metode konstruksi tersebut akan dinilai sesuai ketersediaan sumber daya pada proyek tersebut. Metode konstruksi eksisting pada proyek yang dijadikan studi kasus adalah menggunakan metode konstruksi top-down. Sehingga data ini akan dijadikan validasi model DSS yang sudah disusun.

Input data model DSS adalah pemberian nilai setiap variabel pada sub kriteria sesuai dengan ketersediaan sumber daya yang dimiliki oleh proyek. Pada penelitian ini, penilaian masih dilakukan secara manual sehingga memerlukan analisa berulang sesuai jumlah metode konstruksi yang diusulkan. Selain itu, penilaian ini masih membutuhkan pakar untuk mengintepretasikan ketersediaan sumber daya terhadap karakteristik/perilaku/sifat yang dibutuhkan oleh setiap metode konstruksi yang diusulkan. Hasil penilaian variabel yang dijadikan input data DSS dapat dilihat pada Tabel 8 .
Tabel 8. Penilaian Ahli Terhadap Variabel Metode Konstruksi

\begin{tabular}{|c|c|c|c|}
\hline \multirow{2}{*}{$\begin{array}{c}\text { No } \\
\text { A }\end{array}$} & \multirow{2}{*}{$\frac{\text { Variabel }}{\text { Sub Kriteria: waktu }}$} & \multicolumn{2}{|c|}{ Penilaian } \\
\hline & & $\begin{array}{l}\text { Top } \\
\text { Down }\end{array}$ & $\begin{array}{c}\text { Bottom } \\
\text { Up }\end{array}$ \\
\hline 1 & Manajerial proyek & 3.56 & 3.11 \\
\hline 2 & Kecelakaan kerja & 4.31 & 3.22 \\
\hline 3 & Finansial proyek & 3.31 & 3.83 \\
\hline 4 & $\begin{array}{l}\text { Ketersediaan } \\
\text { peralatan }\end{array}$ & 3.72 & 3.54 \\
\hline 5 & $\begin{array}{l}\text { Ketersediaan } \\
\text { material }\end{array}$ & 3.72 & 3.59 \\
\hline 6 & Penerapan teknologi & 4.60 & 3.22 \\
\hline 7 & $\begin{array}{l}\text { Produktifitas tenaga } \\
\text { kerja }\end{array}$ & 3.29 & 4.47 \\
\hline 8 & $\begin{array}{l}\text { Karakteristk } \\
\text { lingkungan proyek }\end{array}$ & 4.47 & 1.86 \\
\hline 9 & $\begin{array}{l}\text { Intesnsitas curah } \\
\text { hujan }\end{array}$ & 3.11 & 3.11 \\
\hline B & Sub Kriteria: biaya & & \\
\hline 1 & $\begin{array}{l}\text { Ketepatan metode } \\
\text { pelaksanaan }\end{array}$ & 3.18 & 4.20 \\
\hline 2 & $\begin{array}{l}\text { Kenaikan harga } \\
\text { material }\end{array}$ & 3.83 & 3.59 \\
\hline 3 & $\begin{array}{l}\text { Pengalaman dan } \\
\text { pengetahuan } \\
\text { subkontraktor }\end{array}$ & 3.06 & 4.73 \\
\hline 4 & Perubahan desain & 5.00 & 2.81 \\
\hline 5 & Kerusakan material & 4.60 & 3.11 \\
\hline 6 & Respon masyarakat & 3.22 & 3.22 \\
\hline 7 & $\begin{array}{l}\text { Produktifitas tenaga } \\
\text { kerja }\end{array}$ & 3.20 & 4.11 \\
\hline $\mathrm{C}$ & Sub Kriteria: mutu & & \\
\hline 1 & $\begin{array}{l}\text { Pemeriksaan dan } \\
\text { pengkajian gambar }\end{array}$ & 3.94 & 4.08 \\
\hline 2 & $\begin{array}{l}\text { Monitoring } \\
\text { pekerjaan }\end{array}$ & 3.59 & 4.08 \\
\hline 3 & Pengujian sampling & 3.80 & 3.66 \\
\hline 4 & Ketepatan metode & 3.98 & 3.97 \\
\hline 5 & Pemilihan vendor & 3.46 & 3.34 \\
\hline 6 & Inspeksi alat & 3.18 & 3.34 \\
\hline 7 & Supervisi & 3.59 & 3.94 \\
\hline
\end{tabular}


Penilaian pada Tabel 8 dilakukan melalui indepth-interview dengan project manager, site manager dan site engineer. Pada wawancara ini ahli/praktisi diminta memberikan penilaian berdasarkan intepretasi kesesuaian metode konstruksi yang diusulkan (top-down dan bottom-up) dengan keberadaan sumber daya yang dimiliki pada proyek yang sedang dikerjakan. Pada penelitian ini, penilaian dilakukan dengan menggunakan skala linkert, yaitu 1 (paling tidak sesuai) sampai dengan 5 (paling sesuai). Sebagai contoh pada variabel manajerial proyek, para ahli/praktisi diminta untuk memberikan nilai kesiapan manajemen proyek di lapangan saat ini dalam menjalankan metode konstruksi top-down dan bottom-up. Manajemen proyek yang dimaksud meliputi tim proyek, kondisi site proyek, peralatan dan lain-lain. Dari hasil interview diperoleh nilai rata-rata bahwa secara manajerial proyek mereka memberikan nilai 3.56 untuk top-down dan 3.11 untuk bottom-up. Hal ini menunjukkan bahwa para praktisi lebih memilih menggunakan metode konstruksi top-down dari pada bottom-up. Pada variabel kecelakaan kerja, para ahli/praktisi menilai bahwa metode topdown memiliki kemungkinan kecelakaan yang relatif lebih kecil dari pada metode bottom-up, sehingga hasil penilaian ratarata masing-masing metode konstruksi adalah 4.31 dan 3.22 (top-down dan bottomup). Demikian seterusnya dilakukan penilaian pada semua variabel pada sub kriteria yang terdapat pada Tabel 8.

Model analisis data merupakan sistem komputasi untuk membantu memberikan nilai yang terbaik dalam memilih alternatif metode konstruksi yang diusulkan. Sistem komputasi ini menggunakan bobot nilai hasil luaran AHP pada Tabel 7.

Selanjutnya, luaran model DSS dapat diperoleh setelah memasukkan input pada data management system berdasarkan data pada alternatif metode konstruksi untuk dianalisis lebih lanjut dengan model analisis data. Adapun rekapitulasi kriteria hasil luaran model DSS dapat dilihat pada Tabel 9.
Tabel 9. Luaran Model DSS Metode Konstruksi Pekerjaan Basement

\begin{tabular}{llrr}
\hline \multirow{2}{*}{ No } & \multirow{2}{*}{ Kriteria } & \multicolumn{2}{c}{ Nilai } \\
\cline { 3 - 4 } & & Top down & Bottom up \\
\hline 1 & Waktu & 100.7409 & 89.9544 \\
2 & Biaya & 36.2096 & 35.5742 \\
3 & Mutu & 233.8799 & 242.8917 \\
\hline & Total Nilai & 370.8305 & 368.4203 \\
\hline
\end{tabular}

Model DSS merekomendasi bahwa metode konstruksi top-down lebih sesuai jika dibandingkan dengan metode konstruksi bottom-up. Hal ini dapat dilihat dari total nilai yang dihasilkan untuk metode konstruksi top-down sebesar 370.83 sedangkan metode konstruksi bottom-up memiliki nilai 368.42. Jika dianalisa lebih mendetail, maka dapat disimpulkan bahwa metode konstruksi top-down lebih mengutamakan kriteria waktu dan biaya, sedangkan kriteria mutu lebih diprioritaskan pada metode konstruksi bottom-up. Hal ini menunjukkan bahwa metode konstruksi top-down diprediksi dapat mempercepat penyelesaian pekerjaan dan pembiayaan yang lebih terkontrol, sedangkan mutu pekerjaan metode konstruksi top-down dinilai relatif lebih kecil karena pengendalian mutu lebih sulit dibandingkan metode konstruksi bottomup.

\section{Validasi model sistem pengambilan keputusan/Decision Support System (DSS) berbasis AHP}

Validasi model DSS dilakukan dengan menggunakan data metode pelaksanaan proyek eksisting yang dijadikan studi kasus. Validasi ini dilakukan berdasarkan penilaian dari project manager, site manager dan site engineer pada proyek tersebut terhadap hasil luaran model DSS. Adapun hasil validasi tersebut dapat dijelaskan sebagai berikut:

a. Metode konstruksi yang digunakan adalah top-down dan sesuai dengan rekomendasi luaran model DSS. 
b. Tinjauan alasan pemilihan metode topdown di proyek berdasarkan interview dengan tim proyek adalah: (i) faktor keselamatan pada saat pekerjaan galian basement dikarenakan oleh kondisi tanah yang sangat buruk; (ii) site proyek yang relatif sempit serta berhimpitan dengan gedung tinggi disekitarnya; dan (iii) keberadaan sumber daya yang sudah dimiliki oleh kontraktor. Jika dibandingkan dengan luaran model DSS pada Tabel 8 dan 9 yaitu kecelakaan kerja dan pengaturan site termasuk dalam kriteria waktu sedangkan keberadaan sumber daya masuk dalam kriteria biaya, dimana pada kedua kriteria tersebut termasuk kriteria yang direkomendasikan menggunakan metode konstruksi top-down. Dengan demikian maka model DSS ternyata sesuai dengan aplikasi pelaksanaan metode pelaksanaan di proyek.

\section{KESIMPULAN}

a. Metode AHP dapat digunakan untuk menentukan nilai bobot prioritas kriteria variabel penyusun metode konstruksi dengan kriteria mutu (63.75\%) sebagai prioritas utama diikuti waktu (26.65\%) dan biaya (9.60\%).

b. Model DSS dapat disusun menggunakan luaran AHP yang dimodifikasi dan diverifikasi oleh pakar dengan dashboard: User Interface, Data Management System dan Model Analisis Data.

c. Luaran hasil model DSS berbasis AHP dapat menghasilkan keputusan yang sama pada proyek yang dijadikan studi kasus berdasarkan hasil validasi model.

\section{DAFTAR PUSTAKA}

[1] J. W. Soetjipto, "Analisa Perbandingan Pelaksanaan Pembangunan Menggunakan Beton Konvensional dengan Elemen Beton Pracetak pada Bangunan Tingkat Tinggi," Diagonal, vol. 5, no. October, pp. 1-15, 2014.

[2] F. Prawidiawati, Analisa Perbandingan Metode Bottom-Up dan Metode Top-Down Pekerjaan Basement Pada Gedung Parkir Apartemen Skyland City Education Park Bandung Dari Segi Biaya Dan Waktu, 1st ed. SUrabaya: ITS Surabaya, 2015.

[3] C. B. Prawidiawati, F.; Nurcahyo, "Analisa Perbandingan Metode Bottom-Up dan Metode Top-Down Pekerjaan Basement pada Gedung Parkir Apartemen Skyland City Education Biaya Waktu," J. Tek. Its, vol. 4, no. 1, pp. 1-5, 2015.

[4] M. Tanubrata, "Pelaksanaan Konstruksi Dengan Sistem TopDown," in Simposium Nasional RAPI XIV, 2015, pp. 289-293.

[5] P. N. Alifani, R. M. Kurnia, and A. B. Broto, "Tinjauan Metode Konstruksi Top-Down Dan Bottom-Up Berdasarkan Biaya Dan Waktu," in Seminar Nasional Teknik Sipil Politeknik Negeri Jakarta, 2019, pp. 551-560.

[6] J. E. Leal, “AHP-express: A simplified version of the analytical hierarchy process method," MethodsX, vol. 7, 2020, doi: 10.1016/j.mex.2019.11.021.

[7] R. Harianto, T. Sipil, U. Mercubuana, B. Susetyo, T. Sipil, and U. Mercubuana, "Pemilihan Kontraktor Spesialis oleh Kontraktor Utama dengan Metode Analytical Hierarchy Proces," J. Konstr., vol. 12, no. 1, pp. 45-52, 2020.

[8] X. Deng, Y. Hu, Y. Deng, and S. Mahadevan, "Supplier selection using AHP methodology extended by D numbers," Expert Syst. Appl., vol. 41, no. 1, pp. 156-167, 2014, doi: 10.1016/j.eswa.2013.07.018.

[9] P. Parthiban, H. . Zubar, and C. . Garge, "A Multi Criteria Decision Making Approach for Suppliers 
Selection," Procedia Eng., vol. 38, no. 2012, pp. 2312-2328, 2012.

[10] B. Anjasmoro, S. Suharyanto, and S. Sangkawati, "Analisis Prioritas Pembangunan Embung Metode Cluster Analysis, AHP dan Weighted Average (Studi Kasus: Embung di Kabupaten Semarang)," Media Komun. Tek. Sipil, vol. 21, no. 2, p. 101, 2016, doi: 10.14710/mkts.v21i2.11236.

[11] M. Kassab, T. Hegazy, and K. Hipel, "Computerized DSS for Construction Conflict Resolution under Uncertainty," J. Constr. Eng. Manag., vol. 136, no. 12, pp. 1249-1257, 2010, doi: 10.1061/(asce)co.19437862.0000239.

[12] R. Mohemad, A. R. Hamdan, Z. A. Othman, and N. M. M. Noor, "Decision Support Systems (DSS) in Construction Tendering Processes," Int. J. Comput. Sci. Issues, vol. 7, no. 2, pp. 35-45, 2010, [Online]. Available: http://arxiv.org/abs/1004.3260.

[13] I. Herman Firdaus, G. Abdillah, F. Renaldi, and U. Jenderal Achmad Yani Jl, "Sistem Pendukung Keputusan Penentuan Karyawan Terbaik Menggunakan Metode Ahp Dan Topsis," in Seminar Nasional Teknologi Informasi dan Komunikasi, 2016, vol. 2016, no. Sentika, pp. 2089-9815.

[14] Narti, "Sistem Pendukung Keputusan Pemilihan Siswa Berprestasi Menggunakan Metode AHP Dan Topsis," J. Inform., vol. 4, no. 2, pp. 196-205, 2017. 
